\title{
ORIGINAL
}

\section{Sonographic evaluation of cervical nerve roots in ALS and its clinical subtypes}

\author{
Atsuko Mori ${ }^{1}$, Hiroyuki Nodera ${ }^{1}$, Naoko Takamatsu $^{1,2}$, Keiko Maruyama-Saladini ${ }^{1}$, Yusuke Osaki ${ }^{1}$, \\ Yoshimitsu Shimatani ${ }^{1}$, Masaya Oda ${ }^{2}$, Yuishin Izumi ${ }^{1,2}$, and Ryuji Kaji ${ }^{1}$ \\ ${ }^{1}$ Department of Neurology, Tokushima University, Tokushima, Japan, ${ }^{2}$ Department of Neurology, Vihara Hananosato Hospital, Hiroshima, \\ Japan
}

\begin{abstract}
Morphological assessment of peripheral nerves in amyotrophic lateral sclerosis (ALS) has been available by sonography. Detection of possible axonal atrophy could be important in predicting progression. Research on correlation between sonographic findings and clinical presentation has been sparse. The aim of the study was to assess possible motor axon loss in patients with ALS by sonography and to correlate the imaging features with clinical subtypes. Patients with either definite or probable ALS and control subjects had sonographic evaluation of the cervical nerve roots (C5, C6, and C7). Each diameter and their sums were measured. The ALS patients were classified by their clinical onset and progression (arm-onset, leg-onset, bulbar, and flail-arm variant) and the sonographic features were compared. Overall, the cervical nerve roots were thinner in ALS than in the controls, but the diagnostic sensitivity was low. The patients with arm dysfunctions tended to show thinner nerve roots than those with normal or relatively preserved arm functions. The four ALS subtypes showed similar diameters of the nerve roots. There was no correlation between the disease duration and the diameters of the nerve roots. Sonography of the cervical nerve roots showed axonal atrophy in ALS and potentially reflects subtle arm dysfunctions. J. Med. Invest. 63 : 54-57, February, 2016
\end{abstract}

Keywords : ALS, nerve root, sonography, atrophy, onset

\section{INTRODUCTION :}

Amyotrophic lateral sclerosis (ALS) is a progressive neurodegenerative disease that predominantly affects the upper and lower motor neurons. Neuropathological studies have shown atrophy of peripheral nerves and preferentially ventral nerve roots in ALS (1). Because reinnervation could maintain motor units to some extent, detection of motor unit loss is not always straightforward, especially in strong muscles. Therefore, a measure to potentially detect early axon loss should be clinically useful.

For that purpose, high-resolution sonography has been utilized in ALS and different groups consistently reported thinning of various portions of peripheral nerves (2-4). Schreiber and colleagues reported thinning of ulnar nerves in different subtypes of ALS, primarily based on the involvement of the upper and lower motor neurons (4). Because evaluation of cervical roots might provide information in the proximal muscles innervated by $\mathrm{C} 5, \mathrm{C} 6$, and $\mathrm{C} 7$ nerve roots, sonographic evaluation of peripheral nerve (e.g., median and ulnar nerves) as well as cervical nerve roots would be useful (3). Another question remains whether sonography can be a sensitive marker to detect neurodegeneration, especially in was to assess the possible degeneration of the cervical nerve roots in a large number of ALS patients by sonography and its relation with the clinical subtypes. clinically preserved regions. Thus, the aim of the present study

\section{MATERIALS AND METHODS :}

\section{Inclusion criteria of the ALS patients and control subjects}

The following two groups were recruited and prospectively assessed : (A) ALS : the patients who fulfilled the criteria for definite or probable ALS according to the revised El Escorial ALS criteria (5) combined with the Awaji electrodiagnostic criteria (6). Briefly, Awaji electrodiagnostic criteria recognizes fasciculation potential as a sign of active denervation along with fibrillation and positive sharp wave, provided that concurrent evidence of reinnervation is present in the same muscle (i.e., long-duration, high-amplitude motor units, late recruitment, polyphasia). Given the potential disagreement of how the Awaji criteria and the revised El Escorial criteria are to be combined (7), both clinically probable and laboratory-supported probable criteria were enrolled as originally stated in the revised El Escorial criteria (5). The patients were classified into four subtypes based on the initial region of clinical involvement and its progression (arm, leg, bulbar, and flail arm), according to the clinical history and initial neurological examination by a neurologist. The flail arm subtype was defined as reported by Wijesekera, et al. (8). (B) Controls : asymptomatic persons who had no neurological symptom or sign. Specifically, an individual who reported symptoms suggesting cervical radiculopathy (e.g., neck pain, radicular pain, a history of whiplash injury), carpal tunnel syndrome (e.g., hand pain/paresthesia, nocturnal exacerbation, use-related exacerbation) and ulnar neuropathy (e.g., hand pain/paresthesia, elbow injury, elbow pain) were excluded. All the patients with ALS had plain cervical x-ray and showed no clear

Received for publication August 11, 2015 ; accepted September 30, 2015.

Abbreviations :

ALS= amyotrophic lateral sclerosis

ALSFRS-R=ALS Functional Rating Scale-Revised
Address correspondence and reprint requests to Hiroyuki Nodera, MD, and Yuishin Izumi, MD, PhD, Department of Neurology, 3-18-15 Kuramotocho, Tokushima City, 770-8503 Japan. 
evidence of significant cervical spondylosis potentially associated with cervical radiculopathy or myelopathy. At the time of the sonography, the ALS patients had the ALS Functional Rating ScaleRevised (ALSFRS-R). The study was approved by the Institutional Review Board of Vihara Hananosato Hospital and Tokushima University. The subjects gave written informed consent at the time of the testing.

\section{Sonography}

The sonographic examinations were performed using LOGIQ7 (GE) with an 11- $\mathrm{MHz}$ linear-array transducer. A single technician (N.T.) who was not aware of the diagnosis performed the sonography. The participants were tested in the supine position with the arm supinated and abducted at body level. For imaging of the cervical nerve roots, a coronal oblique plane was used to visualize the cervical nerve roots longitudinally. By using the previously described methods the right $\mathrm{C} 5, \mathrm{C} 6$, and $\mathrm{C} 7$ nerve roots were easily identified $(3,9)$. To obtain optimal images for measurements of maximal diameter, the cervical nerve roots were examined in the sagittal oblique plane in addition to the coronal oblique plane in some cases. Color Doppler imaging distinguished the cervical nerve roots from vessels, confirming no flow signals in the cervical nerve roots. The room temperature was maintained at 23-25 degrees Centigrade. The skin temperature at the neck was measured and maintained $>32$ degrees Centigrade by covering a blanket.

SPSS (version 20.0J) (Tokyo, Japan) was used for statistical analysis, using Welch's test, One-way ANOVA with Games-Howell post-hoc test, Fisher's exact test, where applicable. A statistically significant $P$ value was set at 0.05 .

\section{RESULTS :}

The clinical characteristics of the patients and control subjects are shown in Table 1 . The ALS patents were older than the control and more dominated by men (see below for the effects on the sonographic data). The height, weight, and body mass index showed no significant difference. The diameters of the cervical nerve roots in the control subjects were similar to the previous study (10) and thicker than the ALS group (Table 2). However, the proportions of the abnormal diameters in the ALS were low (6-20\%). Multiple regression analysis of the control subjects showed no significant correlation between the sonographic data and either of the following : age, gender, height, weight, or body mass index. The ALS patients were divided according to the ALS-FRS arm subscore. The patients with normal or relatively functional arm functions (i.e., the score was either 11 or $12: \mathrm{n}=16$ ) tended to show thicker cervical roots (C5, C6, and the sum of $\mathrm{C} 5-\mathrm{C} 7)$ than the patients with dysfunctional arms (i.e., the score $\leq 10: \mathrm{n}=35)(P=$ $0.08-0.10)$. However, the disease duration and the cervical root diameters showed no significant correlation.

The sonographic data according to the clinical subtypes in ALS are shown in Table 3 . The patients with flail-arm subtype was older than the arm subtype. Otherwise, these was no difference in the gender and disease durations among the subtypes. The ALS-FRS scores were also similar, but its arm-subscore was lower in the flail-arm subtype than the others. The diameters of the cervical roots were similar among the subtypes (Figure 1).

\section{DISCUSSION :}

In this study we have performed sonographic evaluation of cervical nerve roots in the patients with ALS. The nerve roots were thinner in ALS than in the control subjects, possibly more so in the patients with significant disability. Nerve roots did not show
Table 1 : clinical characteristics of the control subjects and ALS patients

\begin{tabular}{|l|c|c|c|}
\hline & Control & ALS & $P$ value \\
\hline Number & 37 & 51 & \\
\hline Age & $\begin{array}{c}55.3 \pm 8.3 \\
(45-79)\end{array}$ & $\begin{array}{c}67.9 \pm 10.3 \\
(38-88)\end{array}$ & $<0.01$ \\
\hline $\begin{array}{l}\text { Gender } \\
\text { (men/women) }\end{array}$ & $13 / 24$ & $31 / 20$ & 0.02 \\
\hline $\begin{array}{l}\text { Disease duration } \\
\text { (months) }\end{array}$ & N/A & $\begin{array}{c}48.8 \pm 188 \\
(1-1370)\end{array}$ & \\
\hline Height (cm) & $\begin{array}{c}158 \pm 9.0 \\
(145-173)\end{array}$ & $\begin{array}{c}159 \pm 9.0 \\
(134-173)\end{array}$ & 0.8 \\
\hline Weight (kg) & $\begin{array}{c}57.6 \pm 13.4 \\
(36-86)\end{array}$ & $\begin{array}{c}52.9 \pm 9.7 \\
(31-73)\end{array}$ & 0.3 \\
\hline Body Mass Index & $\begin{array}{c}22.5 \pm 3.3 \\
(17.1-29.1)\end{array}$ & $\begin{array}{c}21.0 \pm 3.3 \\
(14.5-27.8)\end{array}$ & 0.15 \\
\hline ALS-FRS & N/A & $\begin{array}{c}39.3 \pm 6.9 \\
(19-48)\end{array}$ & \\
\hline
\end{tabular}

Table 2 : sonographic characteristics of the control subjects and ALS patients

\begin{tabular}{|c|c|c|c|}
\hline & Control & ALS & $P$ value \\
\hline Number & 37 & 51 & \\
\hline $\begin{array}{l}\text { C5 diameter } \\
(\mathrm{mm})\end{array}$ & $\begin{array}{c}2.41 \pm 0.4 \\
\text { (reference : } 1.4-3.3 \text { ) }\end{array}$ & $\begin{array}{c}1.93 \pm 0.6 \\
\text { (18\% abnormal) }\end{array}$ & $<0.001$ \\
\hline $\begin{array}{l}\text { C6 diameter } \\
(\mathrm{mm})\end{array}$ & $\begin{array}{c}3.16 \pm 0.4 \\
\text { (reference : } 2.4-3.9 \text { ) } \\
\end{array}$ & $\begin{array}{c}2.71 \pm 0.5 \\
(20 \% \text { abnormal) } \\
\end{array}$ & $<0.001$ \\
\hline $\begin{array}{l}\text { C7 diameter } \\
(\mathrm{mm})\end{array}$ & $\begin{array}{c}3.77 \pm 0.5 \\
\text { (reference }: 2.8-4.7 \text { ) }\end{array}$ & $\begin{array}{c}3.41 \pm 0.5 \\
(6 \% \text { abnormal })\end{array}$ & $<0.01$ \\
\hline $\begin{array}{l}\text { Sum of } \\
\text { C5-C7 diameters } \\
(\mathrm{mm})\end{array}$ & $\begin{array}{c}9.34 \pm 1.3 \\
\text { (reference : } 6.6-11.9)\end{array}$ & $\begin{array}{c}7.98 \pm 1.3 \\
(14 \% \text { abnormal })\end{array}$ & $<0.001$ \\
\hline
\end{tabular}

significant difference among ALS subtypes.

Sonographic evaluation of peripheral nerves in ALS and related diseases

To reflect axonal degeneration, nerve roots and peripheral nerves in ALS become atrophied $(11,12)$. Clinically, however, this axonal degeneration may not be obvious ; as long as loss of motor axons is compensated by reinnervation by surviving axons, muscle strength could remain intact, as often seen in post-polio syndrome. In that case, preclinical detection of motor axon loss is possible by either physiologically (e.g., needle electromyography) or by imaging studies. Among noninvasive imaging studies, sonography has been reported to be useful in detecting morphological abnormalities, such as abnormal thinning/swelling as well as fascicular involvement in various neuromuscular diseases (13).

In ALS, previous reports consistently suggested thinness in the peripheral nerves by sonography (2-4). At the authors' knowledge, we were the first to report the thinness of cervical nerve roots in ALS and further showed that the diagnostic sensitivity to detect thinness was greater in the cervical nerve roots than the peripheral nerves (median and ulnar nerves) (3). Because the report studied relatively small number of the subjects, further analysis such as correlation with its clinical subtypes was not performed. In the present study, the number of the ALS patients was increased to 51 .

\section{Clinical significance}

The present data suggest several points that are relevant to clinical practice. First, this report supports the traditional notion that 
Table 3 : comparison of the ALS patients according to the clinical subtype on the sonographic parameters

\begin{tabular}{|c|c|c|c|c|c|}
\hline & $\begin{array}{l}\text { Arm-onset } \\
(\mathrm{n}=14)\end{array}$ & $\begin{array}{l}\text { Leg-onset } \\
(\mathrm{n}=14)\end{array}$ & $\begin{array}{c}\text { Bulbar-onset } \\
(\mathrm{n}=15)\end{array}$ & $\begin{array}{c}\text { Flail arm } \\
(\mathrm{n}=8)\end{array}$ & $\begin{array}{c}\text { ANOVA } \\
\text { Significance/post-hoc } \\
P \text { value }\end{array}$ \\
\hline Age (years) & $\begin{array}{c}62.7 \pm 12.7 \\
(38-80)\end{array}$ & $\begin{array}{c}67.6 \pm 9.2 \\
(42-82)\end{array}$ & $\begin{array}{c}70.2 \pm 6.1 \\
(61-82)\end{array}$ & $\begin{array}{c}77.0 \pm 8.6 \\
(65-88)\end{array}$ & $\begin{array}{c}0.02 \\
(P=0.02 \text { (arm vs. flail arm) }\end{array}$ \\
\hline $\begin{array}{l}\text { Gender } \\
\text { (men/women) }\end{array}$ & $11 / 3$ & $7 / 7$ & $9 / 6$ & $4 / 4$ & 0.4 \\
\hline $\begin{array}{l}\text { Disease duration } \\
\text { (months) }\end{array}$ & $\begin{array}{c}24.3 \pm 27.4 \\
(3-104)\end{array}$ & $\begin{array}{c}130.3 \pm 358.4 \\
(3-1370)\end{array}$ & $\begin{array}{c}11.5 \pm 9.3 \\
(1-36)\end{array}$ & $\begin{array}{c}20.9 \pm 17.9 \\
(2-48)\end{array}$ & 0.3 \\
\hline $\begin{array}{l}\text { ALS-FRS } \\
\text { (range : } 0-48 \text { ) }\end{array}$ & $\begin{array}{c}42.2 \pm 6.7 \\
(27-47)\end{array}$ & $\begin{array}{c}36.2 \pm 9.8 \\
(19-48)\end{array}$ & $\begin{array}{c}39.5 \pm 4.4 \\
(31-46)\end{array}$ & $\begin{array}{c}37.7 \pm 4.5 \\
(33-42)\end{array}$ & 0.4 \\
\hline $\begin{array}{l}\text { ALS-FRS arm score } \\
\text { (range : } 0-12 \text { ) }\end{array}$ & $\begin{array}{c}9.7 \pm 1.1 \\
(8-11)\end{array}$ & $\begin{array}{l}9.2 \pm 2.2 \\
(7-12)\end{array}$ & $\begin{array}{c}10.5 \pm 1.4 \\
(8-12)\end{array}$ & $\begin{array}{c}4.7 \pm 3.5 \\
(1-8)\end{array}$ & $\begin{array}{c}0.001 \\
(P<0.05: \text { flail arm })\end{array}$ \\
\hline $\begin{array}{l}\text { C5 diameter }(\mathrm{mm}) \\
\text { (reference : } 1.4-3.3 \text { ) }\end{array}$ & $\begin{array}{l}1.71 \pm 0.6 \\
(0.7-2.9) \\
\end{array}$ & $\begin{array}{l}1.98 \pm 0.4 \\
(1.5-2.3)\end{array}$ & $\begin{array}{c}2.08 \pm 0.7 \\
(0.9-2.9) \\
\end{array}$ & $\begin{array}{l}1.94 \pm 0.5 \\
(1.0-2.6)\end{array}$ & 0.3 \\
\hline $\begin{array}{l}\text { C6 diameter }(\mathrm{mm}) \\
\text { (reference }: 2.4-3.9 \text { ) }\end{array}$ & $\begin{array}{c}2.53 \pm 0.4 \\
(1.9-3.2) \\
\end{array}$ & $\begin{array}{c}2.88 \pm 0.5 \\
(2.0-3.9) \\
\end{array}$ & $\begin{array}{l}2.72 \pm 0.6 \\
(1.7-3.4) \\
\end{array}$ & $\begin{array}{l}2.73 \pm 0.3 \\
(2.2-3.0) \\
\end{array}$ & 0.3 \\
\hline $\begin{array}{l}\text { C7 diameter }(\mathrm{mm}) \\
\text { (reference }: 2.8-4.7)\end{array}$ & $\begin{array}{l}3.44 \pm 0.6 \\
(2.6-4.4)\end{array}$ & $\begin{array}{l}3.39 \pm 0.6 \\
(2.6-4.7)\end{array}$ & $\begin{array}{l}3.49 \pm 0.3 \\
(3.1-4.4)\end{array}$ & $\begin{array}{l}3.23 \pm 0.3 \\
(2.8-3.5)\end{array}$ & 0.7 \\
\hline $\begin{array}{l}\text { Sum of } \\
\text { C5-C7 diameters } \\
\text { (reference : 6.6-11.9) }\end{array}$ & $\begin{array}{l}7.69 \pm 1.2 \\
(5.3-9.9)\end{array}$ & $\begin{array}{l}8.25 \pm 1.2 \\
(6.1-9.9)\end{array}$ & $\begin{array}{l}8.06 \pm 1.7 \\
(5.7-10.3)\end{array}$ & $\begin{array}{l}7.9 \pm 0.6 \\
(6.6-8.6)\end{array}$ & 0.7 \\
\hline
\end{tabular}

A
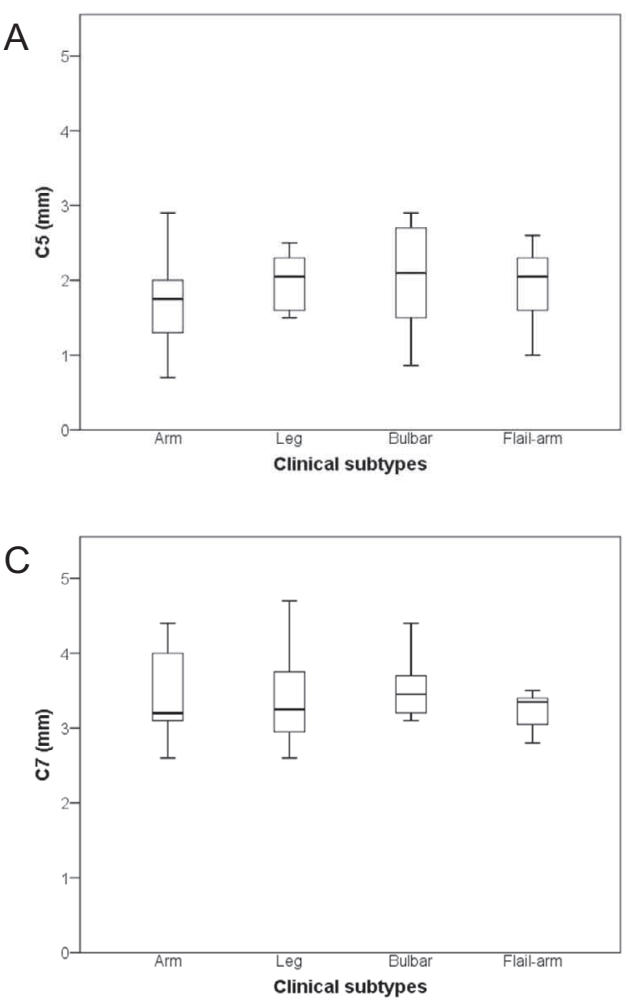

B

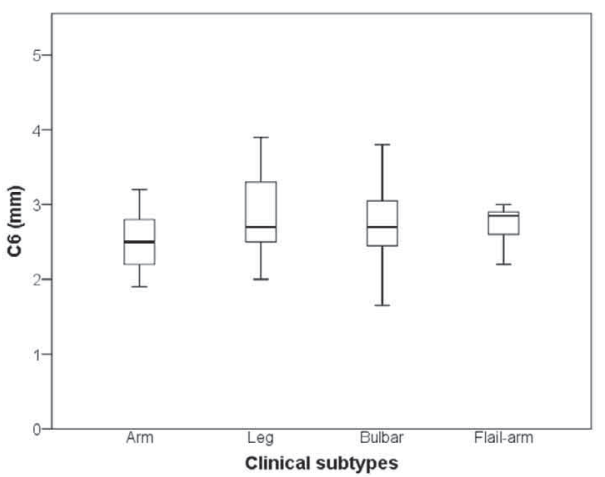

D

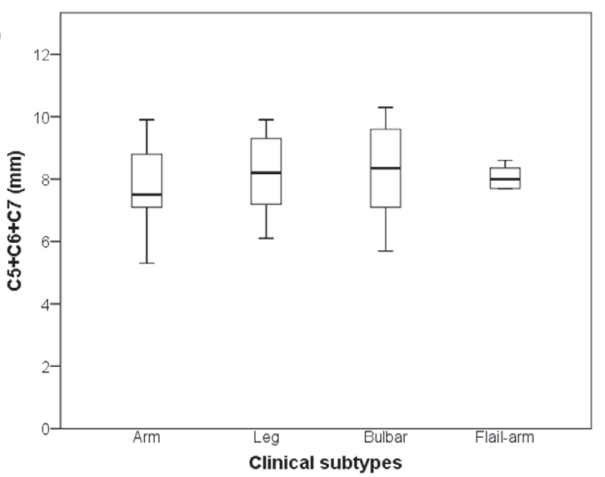

Figure 1 : The diameters and the sums are shown according to the clinical subtypes of ALS. No significant difference was present among the subtypes.

the diagnosis of ALS should be based on the clinical basis, possibly aided by electrophysiology. Detection of axonal degeneration by needle electromyography could be much greater than sonographic evaluation of axonal thinning. A note should be made, however, on muscle sonography because sonography would have greater sensitivity for detection of fasciculations than needle electromyography (14). Second, on the other hand, our data also suggest potential utility of sonography to detect subtle axon loss in clinically relatively preserved regions, because of similar axon sizes between the arm-onset and the leg-onset groups. Propagation of the pathogenetic process could be detected by neurophysiological and neuroimaging modalities. Third, in comparison with commonly tested peripheral nerves in the arm (ulnar and median nerves), sonographic evaluation of cervical roots assesses potential loss of axons that innervate proximal muscles. Combination of nerve roots and peripheral nerves for sonographic evaluation should cover axons 
innervating wider ranges of muscles than only assessing either one, but this hypothesis should be tested by a larger-scale prospective study.

\section{Limitation of the study}

This study has limitations. First, sonographic evaluation was performed only once, thus it is unknown whether sonographic evaluation of nerve roots is useful as a disease marker for disease progression. Second, because of heterogeneous clinical presentation of ALS, our patients were in different disease stages that may have limited the diagnostic sensitivity of sonography. Third, although we tried hard to have blinded sonographic evaluation, recognition of ALS is often straightforward and completely blinded evaluation was not possible. Fourth, although our analysis did not show an age-effect on the nerve size, two groups reported slight age effects, especially in the distal part of peripheral nerves $(10,15)$. Because our ALS patients were older than the control subjects, the diagnostic sensitivity could have been underpowered.

\section{CONFLICT OF INTEREST STATEMENT :}

None of the authors has conflict of interest.

\section{ACKNOWLEDGEMENT :}

This work was supported by Grants-in-Aid from the Research Committee of CNS Degenerative Diseases, the Ministry of Health, Labour and Welfare of Japan. None of the authors has conflict of interest.

\section{REFERENCES :}

1. Sobue G, Hashizume Y, Mitsuma T, Takahashi A : Size-dependent myelinated fiber loss in the corticospinal tract in ShyDrager syndrome and amyotrophic lateral sclerosis. Neurology 37: 529-32, 1987

2. Cartwright MS, Walker FO, Griffin LP, Caress JB : Peripheral nerve and muscle ultrasound in amyotrophic lateral sclerosis. Muscle Nerve 44 : 346-51, 2011

3. Nodera H, Takamatsu N, Shimatani Y, Mori A, Sato K, Oda M, Terasawa Y, Izumi Y, Kaji R: Thinning of cervical nerve roots and peripheral nerves in ALS as measured by sonography. Clin Neurophysiol 125 : 1906-11, 2014

4. Schreiber S, Abdulla S, Debska-Vielhaber G, Machts J, Dannhardt-Stieger V, Feistner H, Oldag A, Goertler M, Petri
S, Kollewe K, Kropf S, Schreiber F, Heinze HJ, Dengler R, Nestor PJ, Vielhaber S : Peripheral nerve ultrasound in amyotrophic lateral sclerosis phenotypes. Muscle Nerve, 2014

5. Brooks BR, Miller RG, Swash M, Munsat TL: El Escorial revisited : revised criteria for the diagnosis of amyotrophic lateral sclerosis. Amyotroph Lateral Scler Other Motor Neuron Disord $1: 293-9,2000$

6. de Carvalho M, Dengler R, Eisen A, England JD, Kaji R, Kimura J, Mills K, Mitsumoto H, Nodera H, Shefner J, Swash $\mathrm{M}$ : Electrodiagnostic criteria for diagnosis of ALS. Clin Neurophysiol 119:497-503, 2008

7. Higashihara M, Sonoo M, Imafuku I, Fukutake T, Kamakura K, Inoue K, Hatanaka Y, Shimizu T, Tsuji S, Ugawa Y : Fasciculation potentials in amyotrophic lateral sclerosis and the diagnostic yield of the Awaji algorithm. Muscle Nerve 45 : 175-82, 2012

8. Wijesekera LC, Mathers S, Talman P, Galtrey C, Parkinson MH, Ganesalingam J, Willey E, Ampong MA, Ellis CM, Shaw CE, Al-Chalabi A, Leigh PN : Natural history and clinical features of the flail arm and flail leg ALS variants. Neurology 72 : 1087-94, 2009

9. Matsuoka N, Kohriyama T, Ochi K, Nishitani M, Sueda Y, Mimori Y, Nakamura S, Matsumoto M : Detection of cervical nerve root hypertrophy by ultrasonography in chronic inflammatory demyelinating polyradiculoneuropathy. J Neurol Sci $219: 15-21,2004$

10. Sugimoto T, Ochi K, Hosomi N, Mukai T, Ueno H, Takahashi T, Ohtsuki T, Kohriyama T, Matsumoto M : Ultrasonographic reference sizes of the median and ulnar nerves and the cervical nerve roots in healthy Japanese adults. Ultrasound in medicine \& biology 39 : 1560-70, 2013

11. Sobue G, Matsuoka Y, Mukai E, Takayanagi T, Sobue I : Pathology of myelinated fibers in cervical and lumbar ventral spinal roots in amyotrophic lateral sclerosis. J Neurol Sci 50 : 413-21, 1981

12. Hanyu N, Oguchi K, Yanagisawa N, Tsukagoshi H : Degeneration and regeneration of ventral root motor fibers in amyotrophic lateral sclerosis. Morphometric studies of cervical ventral roots. J Neurol Sci 55 : 99-115, 1982

13. Suk JI, Walker FO, Cartwright MS : Ultrasonography of peripheral nerves. Curr Neurol Neurosci Rep $13: 328,2013$

14. Misawa S, Noto Y, Shibuya K, Isose S, Sekiguchi Y, Nasu S, Kuwabara S : Ultrasonographic detection of fasciculations markedly increases diagnostic sensitivity of ALS. Neurology $77: 1532-7,2011$

15. Cartwright MS, Mayans DR, Gillson NA, Griffin LP, Walker FO : Nerve cross-sectional area in extremes of age. Muscle Nerve $47: 890-3,2013$ 